\title{
Racial and Ethnic Differences in Breastfeeding
}

Chelsea 0. McKinney, PhD, MPH, a Jennifer Hahn-Holbrook, PhD, ${ }^{\text {P }}$. Lindsay Chase-Lansdale, PhD,

Sharon L. Ramey, PhD, ${ }^{d}$ Julie Krohn, MS, RDN, LDN, ${ }^{e}$ Maxine Reed-Vance, RN, MS, ${ }^{f}$ Tonse N.K. Raju, MD, DCH, 8

Madeleine U. Shalowitz, MD, MBA, a, h on behalf of the Community Child Health Research Network

OBJECTIVES: Breastfeeding rates differ among racial/ethnic groups in the United States. Our aim was to test whether racial/ethnic disparities in demographic characteristics, hospital use of infant formula, and family history of breastfeeding mediated racial/ethnic gaps in breastfeeding outcomes.

METHODS: We analyzed data from the Community and Child Health Network study $(N=1636)$. Breastfeeding initiation, postnatal intent to breastfeed, and breastfeeding duration were assessed postpartum. Hierarchical linear modeling was used to estimate relative odds of breastfeeding initiation, postnatal intent, and duration among racial/ethnic groups and to test the candidate mediators of maternal age, income, household composition, employment, marital status, postpartum depression, preterm birth, smoking, belief that "breast is best," family history of breastfeeding, in-hospital formula introduction, and WIC participation.

RESULTS: Spanish-speaking Hispanic mothers were most likely to initiate (91\%), intend (92\%), and maintain (mean duration, 17.1 weeks) breastfeeding, followed by English-speaking Hispanic mothers (initiation 90\%, intent 88\%; mean duration, 10.4 weeks) and white mothers (initiation 78\%, intent 77\%; mean duration, 16.5 weeks); black mothers were least likely to initiate (61\%), intend (57\%), and maintain breastfeeding (mean duration, 6.4 weeks). Demographic variables fully mediated disparities between black and white mothers in intent and initiation, whereas demographic characteristics and in-hospital formula feeding fully mediated breastfeeding duration. Family breastfeeding history and demographic characteristics helped explain the higher breastfeeding rates of Hispanic mothers relative to white and black mothers.

concLusıons: Hospitals and policy makers should limit in-hospital formula feeding and consider family history of breastfeeding and demographic characteristics to reduce racial/ ethnic breastfeeding disparities.

\footnotetext{
${ }^{a}$ NorthShore University HealthSystem Department of Pediatrics and Research Institute, Evanston, Illinois; ${ }^{b}$ Crean College of Health and Behavioral Sciences, Chapman University, Orange, California; ${ }^{c}$ Institute for Policy

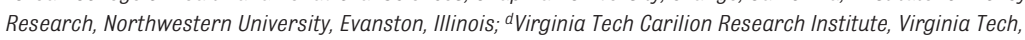
Roanoke, Virginia; ' Lake County Health Department and Community Health Center, Waukegan, Illinois; ${ }^{\circ}$ Baltimore Healthy Start, Inc, Baltimore, Maryland; 'PPregnancy and Perinatology Branch, Eunice Kennedy Shriver National Institute of Child Health and Human Development, National Institutes of Health, Rockville, Maryland; and ${ }^{n}$ Department of Pediatrics, University of Chicago, Pritzker School of Medicine, Chicago, Illinois

Dr McKinney conceptualized the research questions, helped design the data collection instruments, conducted data collection, helped conduct the analyses, and drafted the initial and revised manuscripts; Dr Hahn-Holbrook helped conceptualize the research questions, draft the initial and revised manuscripts, and conduct the analyses; Dr Chase-Lansdale critically reviewed the initial manuscript; Dr Ramey helped design the data collection instruments, coordinated and supervised data collection, and critically reviewed the initial and revised manuscripts; Mrs Krohn helped design the data collection instruments and critically reviewed the initial manuscript; Mrs Vance helped design the data collection instruments, coordinated and supervised data collection,
}

WHAT'S KNOWN ON THIS SUBJECT: Breastfeeding rates differ between racial/ethnic groups in the United States, resulting in considerable health disparities for infants. Black infants are breastfed for substantially shorter periods compared with white infants, and Hispanic infants are breastfed for significantly longer periods.

WHAT THIS STUDY ADDS: We show that demographic characteristics and in-hospital formula feeding explain breastfeeding gaps between black and white mothers, whereas demographic characteristics and family history of breastfeeding help explain higher rates of breastfeeding in Hispanic mothers compared with white and black mothers.

To cite: McKinney CO, Hahn-Holbrook J, Chase-Lansdale PL, et al. Racial and Ethnic Differences in Breastfeeding. Pediatrics. 2016;138(2)::20152388 
Substantial research shows that breastfeeding benefits the neurologic, immunologic, digestive, and physical development of children. ${ }^{1}$ The American Academy of Pediatrics recommends exclusive breastfeeding for the first 6 months of life, with continued breastfeeding and complementary foods at least until the child's first birthday. Despite this recommendation, approximately one-half of children in the United States are no longer breastfed by 6 months, with only a small percentage breastfed for the recommended period of 12 months. ${ }^{2}$ Suboptimal levels of breastfeeding cost the US economy billions of dollars annually ${ }^{3,4}$ and contribute to an estimated 911 (predominantly infant) deaths each year. ${ }^{4}$ Importantly, the social, health, and economic burdens of low breastfeeding rates are not shared equally across racial and ethnic groups.

In the most recent US National Immunization Survey, only $66.4 \%$ of black mothers initiated breastfeeding in 2012, compared with $83 \%$ of white mothers and $82.4 \%$ of Hispanic mothers. ${ }^{2}$ Racial/ethnic gaps in breastfeeding remained significant at 6 months, with only $35.3 \%$ of black mothers still breastfeeding, compared with $55.8 \%$ of white mothers and $51.4 \%$ of Hispanic mothers. Black women consistently remain at the bottom on all breastfeeding indices, although the gap between black mothers and other ethnic groups has narrowed by a few percentage points since 2000 , suggesting breastfeeding promotion efforts have helped.

Many factors have been proposed to explain these racial/ethnic breastfeeding disparities. Black mothers, for example, tend to be younger, unmarried, and of lower income and education compared with white mothers, all factors linked to lower breastfeeding rates. ${ }^{5}$ Interestingly, although Hispanic mothers share many of these demographic characteristics with black mothers, they have higher rates of breastfeeding than white mothers. Moreover, accounting for income and maternal education differences between black and white mothers does not eliminate disparities in breastfeeding. 6,7 To address the persistent large gap in breastfeeding rates between black mothers and mothers of other groups, the current article includes these demographic factors, but it also considers other causes.

The goal of the current study was to identify key nondemographic factors that might explain disparities in breastfeeding among black, white, and Hispanic mothers in the United States. We considered racial/ethnic differences in attitudes toward breastfeeding, family history of breastfeeding, in-hospital formula introduction, and participation in the Special Supplemental Nutrition Program for Women, Infants, and Children. Our objective was to determine whether racial/ethnic disparities in breastfeeding initiation, postnatal intent, and duration could be more fully explained by using statistical mediation techniques that included these hypothesized new factors.

\section{METHODS}

\section{Study Sample}

The sample consisted of 1636 mothers from the Community and Child Health Network, an National Institutes of Health multisite, community-based participatory research project designed to examine how community, family, and individual factors contribute to racial/ethnic health disparities for mothers and infants. The current study uses data from sites in Baltimore, Maryland, Washington, DC, and Lake County, Illinois. Each site sought to include mothers of low socioeconomic status (SES) from the 3 race/ethnicity groups, reflecting the local population; oversampling was included when needed. Data were obtained when mothers enrolled between 2008 and 2010 during their postpartum hospital stay and from in-home interviews 1 and 6 months' postpartum. Mothers included in this study provided infant feeding data (regardless of feeding method) for at least 2 time points. Overall, $<1 \%$ of initiation and postnatal intent data were missing, although $12 \%$ of mothers did not provide breastfeeding duration data and 30\% lacked information on family breastfeeding history. We attempted to address this missing data issue by using the multiple imputation function in Stata, ${ }^{8}$ generating 10 possible data sets from which estimates were pooled.

\section{Measures}

\section{Independent Variables}

Racial/ethnic identification was based on mothers' self-report as either non-Hispanic white (hereafter referred to as white), non-Hispanic black (hereafter referred to as black), or Hispanic. The Community Child Health Research Network was designed to recruit mothers with these primary racial/ethnic identities (irrespective of legal status); thus, $<1 \%$ also identified as other or mixed race. Participants who designated mixed race were placed in either the Hispanic or the black group to which they partially self-identified. Hispanic participants were further categorized as primarily English- or Spanish-speaking because markers of acculturation, including language spoken at home, ${ }^{8}$ have been shown to have a large impact on breastfeeding outcomes. ${ }^{9}$

\section{Potential Mediators}

Candidate mediators were chosen based on known associations with breastfeeding as rereported in the literature. We tested these factors for their ability to mediate or explain a significant proportion 
of the variance in racial/ethnic disparities in breastfeeding outcomes. Demographic factors included maternal age, ${ }^{10}$ education, employment at 1 month postpartum, ${ }^{11}$ poverty status ${ }^{10}$ (adjusted for family size by using federal guidelines ${ }^{12}$ ), relationship status ${ }^{13}$ (single, in a relationship, or married [mutually exclusive categories]), coresident father, ${ }^{14}$ and coresident grandparent. ${ }^{15}$ Health-related variables included 1 month postpartum depression, ${ }^{16}$ according to the Edinburgh Postnatal Depression Scale ${ }^{17}$ (scores $\geq 9$ were categorized as depressed); smoking at 1 month $^{18}$; and infant preterm birth ${ }^{19}$ (via medical records, gestation $<37$ weeks). We also collected maternal and paternal family history of breastfeeding ${ }^{20}$ (determined by asking mothers and fathers "Did the woman who raised you breastfeed any children?") and the mother's belief ${ }^{21}$ that "breast is best" (assessed by asking "Which of the following do you think is the best way to feed a baby-breastfeeding, a mix of breast milk and formula, only formula, or either breast milk or formula?"). Mothers who indicated breastfeeding was the best feeding method were compared with those who did not. Mothers were asked during their in-hospital stay whether they had participated in the Special Supplemental Nutrition Program for Women, Infants, and Children ${ }^{22}$ at any time during the past year. Finally, patient medical records indicated whether formula was introduced during the hospital stay ${ }^{23}$ after birth.

\section{Outcome Variables}

Primary outcomes of interest were breastfeeding initiation, postnatal breastfeeding intent, and breastfeeding duration. Breastfeeding initiation was measured at 1 month postpartum with the question "Have you ever breastfed your baby?" Mothers were categorized as having initiated breastfeeding if they breastfed at least once. Postnatal breastfeeding intent was assessed during the in-hospital interview and derived from the question "How do you plan to feed your baby?" Mothers were categorized as intending to breastfeed if they planned to provide any amount of breast milk or not intending to breastfeed if they planned to provide only infant formula. Breastfeeding duration was defined as the number of weeks that the infant had been breastfed by the 6-month interview. Women who did not initiate breastfeeding were included in our duration measure and coded as 0 . If the mother was no longer breastfeeding at the 1or 6-month interviews, mothers were asked "How old was the child in weeks when you stopped breastfeeding?" to extrapolate total duration.

\section{Statistical Analysis}

Hierarchical linear modeling offers advantages over other statistical tools in evaluating nested data, which, in this case, adjusts for shared variance that participants (level 1) may have if they are from the same site and allows for heterogeneity of effect sizes for different sites (level 2). ${ }^{24}$ All analyses were performed by using multilevel analysis, with study site added to the level 2 regression equation as a random factor, and independent and mediator variables included in univariate and multivariate models in the regression equation at level 1. Comparisons with Hispanic participants excluded the Baltimore site because only 4 Hispanic subjects were recruited, precluding good estimates at level 2. All analyses were conducted by using Stata version 14 (Stata Corp, College Station, TX).

\section{Mediation Analysis}

A mediator is a variable, or set of variables, hypothesized to explain or cause the observed association between an independent variable (ie, race/ethnicity) and a dependent variable (eg, breastfeeding outcome). Using classic mediation criteria, ${ }^{25} \mathrm{a}$ variable can be said to mediate the relationship between an independent and dependent variable (Path C) if: (1) the independent variable significantly accounts for variation in the mediator (Path A); (2) the mediator significantly accounts for variation in the outcome variable (Path B); and (3) both the mediator and the independent variable are included in a multivariate model, and the relationship between the independent variable and the outcome variable is significantly reduced or no longer statistically significant (Path $\mathrm{C}^{\prime}$ ), while the mediator continues to predict significant variation in the outcome variable (Fig 1). There are often multiple mediators or causes of an association between an independent and dependent variable. ${ }^{26}$ The same mediation criteria are used to test multiple mediators; however, all mediators must be added simultaneously to equations testing Path A, Path B, and Path $C^{\prime}$ to ensure that each mediator accounts for a unique proportion of the variance shared between the independent and dependent variable.

Mediation analysis was performed to test whether the candidate mediators helped to explain racial/ethnic breastfeeding disparities (Figs 1 and 2). First, hierarchical linear modeling was used to obtain estimates of racial/ethnic gaps in breastfeeding outcomes (Path C). Racial/ethnic differences in potential mediators were next tested (Path A). The association between these potential mediators and breastfeeding outcomes was then assessed (Path B). Only variables that were significant at Paths C, A, and B, respectively, were considered further. To avoid introducing reverse causality when assessing mediators of racial/ethnic disparities in breastfeeding initiation and postnatal intent, we did not consider variables that occurred 


Race/ethnicity $\rightarrow$ Breastfeeding outcome

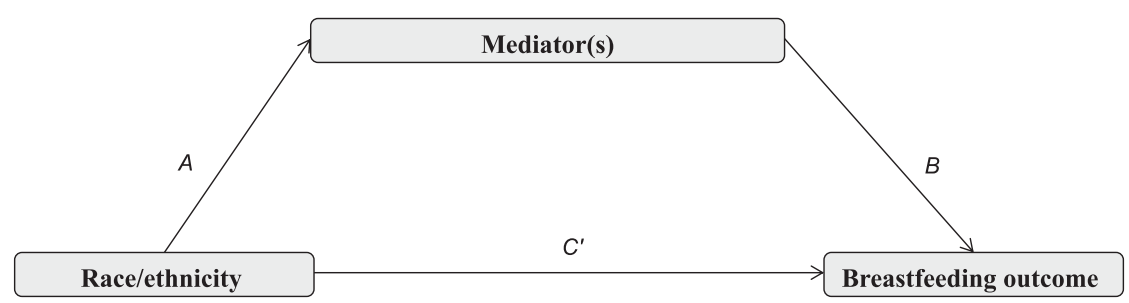

FIGURE 1

Mediation model pathways. Path $C$ and $C^{\prime}$ differ in that path $C$ is the raw association between the independent and outcome variables, and path $\mathrm{C}^{\prime}$ is the residual association between the independent and outcome variables after the indirect effect of the mediator(s) is included in the model. Only racial/ethnic contrasts significant at Path $\mathrm{C}$ were pursued. Of those, mediation analysis was discontinued if Path A was not significant.

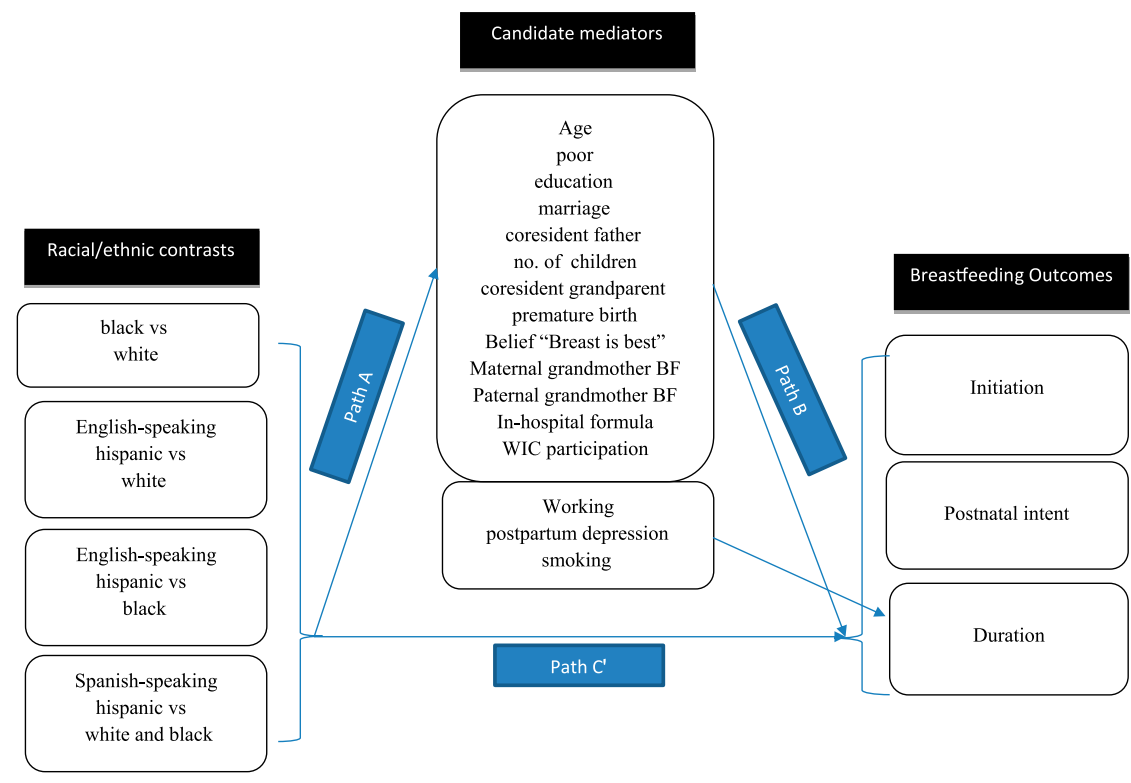

\section{FIGURE 2}

Summary of possible mediation relationships. Working, postpartum depression, and smoking were only tested with duration because they were measured at 1 month postpartum, which occurs after breastfeeding initiation and postnatal intent were measured in the hospital. BF, breastfed; WIC, Special Supplemental Nutrition Program for Women, Infants, and Children.

after the hospital stay (ie, working at 1 month, postpartum depression, smoking). Smoking, for instance, was measured at 1 month postpartum, which occurs after breastfeeding initiation and thus carries no predictive power.

The fourth and final step regressed significant mediator(s) on a breastfeeding outcome, with race/ ethnicity included in the model to estimate the indirect effect (Path $\mathrm{C}^{\prime}$ ).
Sobel tests were performed (data not shown) to ensure that mediators had significant indirect effects $(P<.05)$ when the aforementioned mediation criteria were met. Once mediators are included in the model, a racial/ethnic gap in breastfeeding can be said to be partially mediated if the association between race/ ethnicity and breastfeeding was reduced and $C^{\prime}$ is still statistically significant, and it is fully mediated if $\mathrm{C}^{\prime}$, representing the racial/ethnic disparity in breastfeeding, is no longer statistically significant. ${ }^{25}$ Unstandardized betas $(\beta)$ and confidence intervals are reported.

\section{RESULTS}

Consistent with previous findings, black mothers had significantly lower rates of breastfeeding initiation, postnatal intent, and duration compared with other racial/ethnic groups, whereas Spanish-speaking Hispanic mothers tended to have the highest breastfeeding indicators (Table 1). Many other significant differences emerged between racial/ ethnic groups among our candidate mediator variables (Table 2), and candidate variables that did not differ (Path A) were not considered further. Tables 3, 4, 5, 6, and 7 report regression coefficients for all significant mediation pathways, which are summarized in Fig 1.

\section{Disparities Between Black and White Mothers}

\section{Initiation}

Black mothers were less likely to initiate breastfeeding than white mothers (Table 3, Path C). Black women also experienced higher rates of poverty and were less likely to have a college degree or be married compared with white women, all of which predicted less breastfeeding initiation (Table 3, Paths A and B). Together, poverty, college education, and marital status fully mediated the gap in breastfeeding initiation (Table 3, Path $\mathrm{C}^{\prime}$ ).

\section{Postnatal Intent}

Black mothers were less likely to intend to breastfeed than white mothers (Table 3, Path C). Again, poverty, a college degree, and being married fully mediated the gap in postnatal breastfeeding intent (Table 3, Path C'). 
TABLE 1 Breastfeeding Outcomes According to Race/Ethnicity

\begin{tabular}{|c|c|c|c|c|c|}
\hline Outcome & Total $(N=1632)$ & White $(n=310)$ & Black $(n=907)$ & $\begin{array}{l}\text { Hispanic-Spanish } \\
\quad(n=268)\end{array}$ & $\begin{array}{l}\text { Hispanic-English } \\
\quad(n=147)\end{array}$ \\
\hline Initiation & 72 & $78^{a}$ & $61^{\mathrm{b}}$ & $91^{\mathrm{c}}$ & $90^{c}$ \\
\hline Postnatal intent & 70 & $77^{\mathrm{a}}$ & $57^{b}$ & $92^{\mathrm{C}}$ & $88^{c}$ \\
\hline Duration, mean \pm SD, wk & $10.29 \pm 13.13$ & $16.51^{\mathrm{a}} \pm 15.88$ & $6.40^{b} \pm 9.86$ & $17.09^{a} \pm 14.66$ & $10.44^{\mathrm{c}} \pm 12.50$ \\
\hline
\end{tabular}

Data are presented as the percent mean unless otherwise indicated. Values that differ in superscripts within the same row indicate that there is a significant difference $(P<.05)$ between racial/ethnic groups. (For example: A value with $a$ is significantly different from values with $b, c$, or $d$ in the same row but not different from other values with $a$ in the same row.)

TABLE 2 Differences in Potential Mediators as a Function of Race/Ethnicity

\begin{tabular}{|c|c|c|c|c|c|}
\hline Variable & Total $(N=1632)$ & White $(n=310)$ & Black $(n=907)$ & $\begin{array}{l}\text { Hispanic-Spanish } \\
\quad(n=268)\end{array}$ & $\begin{array}{l}\text { Hispanic-English } \\
\quad(n=147)\end{array}$ \\
\hline Mother's mean age, y & 25.15 & $29.19^{a}$ & $23.82^{a, b}$ & $25.93^{a}$ & $23.38^{c}$ \\
\hline Poor & 40 & $15^{\mathrm{a}}$ & $49^{b}$ & $40^{\mathrm{a}, \mathrm{b}}$ & $36^{a, b}$ \\
\hline Working & 24 & 25 & 24 & 24 & 26 \\
\hline Coresident father & 62 & $86^{\mathrm{a}}$ & $44^{\mathrm{b}}$ & $87^{\mathrm{a}}$ & $78^{a}$ \\
\hline Mean total no. of children & 1.93 & $1.71^{\mathrm{a}}$ & $197^{\mathrm{b}}$ & $2.07^{\mathrm{a}}$ & $1.87^{\mathrm{a}}$ \\
\hline Coresident grandparent & 34 & $16^{\mathrm{a}}$ & $42^{b}$ & $20^{\mathrm{a}, \mathrm{b}, \mathrm{c}}$ & $49^{a, b}$ \\
\hline Postpartum depression & 17 & 14 & 18 & 19 & 17 \\
\hline Smoker & 16 & $24^{\mathrm{a}}$ & $17^{\mathrm{b}}$ & $2^{c}$ & $17^{\mathrm{b}}$ \\
\hline Premature birth & 14 & 15 & 14 & 14 & 18 \\
\hline Maternal grandmother breastfed & 57 & $62^{\mathrm{a}}$ & $39^{a}$ & $93^{b}$ & $77^{\mathrm{b}}$ \\
\hline Paternal grandmother breastfed & 60 & $63^{a}$ & $43^{a}$ & $91^{\mathrm{b}}$ & $76^{\mathrm{b}}$ \\
\hline Mother: "Breastfeeding best for baby" & 41 & 51 & 37 & 46 & 36 \\
\hline WIC participant & 69 & $30^{\mathrm{a}}$ & $75^{b}$ & $89^{c}$ & $76^{\mathrm{b}}$ \\
\hline Fed formula at hospital & 66 & $39^{a}$ & $76^{\mathrm{b}}$ & $68^{a, b}$ & $58^{a, b}$ \\
\hline \multicolumn{6}{|l|}{ Education } \\
\hline Less than high school & 21 & $5^{\mathrm{a}}$ & $18^{\mathrm{a}, \mathrm{b}}$ & $46^{c}$ & $26^{\mathrm{b}, \mathrm{c}}$ \\
\hline (High school or GED) & 41 & 23 & 48 & 40 & 44 \\
\hline Some higher education & 24 & $21^{\mathrm{a}}$ & $28^{\mathrm{a}}$ & $11^{\mathrm{b}}$ & $23^{a}$ \\
\hline College or beyond & 14 & $51^{\mathrm{a}}$ & $6^{\mathrm{b}}$ & $3^{c}$ & $8^{\mathrm{b}}$ \\
\hline \multicolumn{6}{|l|}{ Relationship status } \\
\hline Single & 15 & $6^{\mathrm{a}}$ & $22^{\mathrm{b}}$ & $6^{\mathrm{b}}$ & $9 a, b$ \\
\hline In relationship & 56 & $28^{\mathrm{a}}$ & $65^{\mathrm{b}}$ & $58^{\mathrm{a}, \mathrm{b}}$ & $52^{\mathrm{a}, \mathrm{b}}$ \\
\hline (Married) & 29 & $66^{\mathrm{a}}$ & $13^{b}$ & $36^{a, b}$ & $38^{\mathrm{c}}$ \\
\hline
\end{tabular}

Data are presented as the percent mean unless otherwise indicated. Means represent raw data, without imputation. Parentheses indicate reference category. Values that differ in superscripts within the same row indicate that there is a significant difference $(P<.05)$ between racial/ethnic groups. (For example: A value with $a$ is significantly different from values with $b, c$, or $d$ in the same row but not different from other values with $a$ in the same row.) GED, General Educational Development; WIC, Special Supplemental Nutrition Program for Women, Infants, and Children.

\section{Duration}

Black mothers weaned their infants 10.3 weeks earlier than did white mothers (Table 3, Path C). College education and marital status differed between groups and predicted shorter breastfeeding durations (Table 3, Paths A and B). In addition, white mothers were significantly less likely to experience in-hospital formula introduction than black mothers, which was the biggest predictor of breastfeeding duration, even in models controlling for racial/ ethnic disparities in initiation and postnatal intent. Together, these factors fully mediated the disparity in breastfeeding duration (Table 3, Path $\mathrm{C}^{\prime}$ ). Poverty was not a unique predictor of breastfeeding duration.

\section{Disparities Between White and Spanish-speaking Hispanic Mothers}

\section{Initiation}

Spanish-speaking Hispanic mothers were more likely to initiate breastfeeding compared with white mothers (Table 4, Path C). Spanishspeaking mothers were more likely to have had their own mothers breastfeed children, which predicted higher breastfeeding initiation (Table 4, Paths A and B). Maternal family history of breastfeeding fully mediated the initiation gap between white and Spanish-speaking Hispanic mothers (Table 4, Path $\mathrm{C}^{\prime}$ ).

\section{Postnatal Intent}

Spanish-speaking Hispanic mothers were significantly more likely to intend to breastfeed than were white mothers (Table 4, Path C). However, no variables met mediation criteria.

\section{Duration}

Spanish-speaking Hispanic and white mothers had comparable durations for breastfeeding. Mediation analysis was therefore not pursued. 
Disparities Between White and English-speaking Hispanic Mothers

\section{Initiation}

English-speaking Hispanic mothers exhibited significantly higher rates of initiation than did white mothers (Table 5, Path C). English-speaking mothers were more likely to have had their own mothers breastfeed children, which predicted higher breastfeeding initiation (Table 5, Paths A and B). Maternal family history of breastfeeding fully mediated the initiation gap between white and English-speaking Hispanic mothers (Table 5, Path $\mathrm{C}^{\prime}$ ).

\section{Postnatal Intent}

English-speaking Hispanic mothers were more likely to intend to breastfeed than were white mothers (Table 5, Path C), although no variables met mediation criteria.

\section{Duration}

White mothers breastfed $\sim 6.9$ weeks longer than did English-speaking Hispanic mothers (Table 5, Path C); the latter group tended to be younger and lack a college degree (Table 5, Path A), both of which fully mediated the gap in duration (Table 5, Path $\mathrm{C}^{\prime}$ ).

\section{Disparities Between Black and} Spanish-speaking Hispanic Mothers

\section{Initiation}

Spanish-speaking Hispanic mothers had significantly higher rates of initiation than did black mothers (Table 6, Path C). Spanish-speakers were also more likely to have a mother who had breastfed (Table 6, Path A), which predicted greater breastfeeding initiation in the next generation (Table 6, Path B) and partially mediated this racial/ethnic disparity (Table 6, Path $\mathrm{C}^{\prime}$ ).

\section{Postnatal Intent}

Black mothers were less likely to intend to breastfeed after leaving the hospital than were Spanish-speaking mothers (Table 6, Path C). Having a
TABLE 3 Mediation of Differences in Breastfeeding Initiation, Postnatal Intent, and Duration Between White and Black Mothers

\begin{tabular}{|c|c|c|}
\hline Variable & $\beta$ & 95\% Confidence Interval \\
\hline \multicolumn{3}{|l|}{ Breastfeeding initiation } \\
\hline \multicolumn{3}{|l|}{ Path C } \\
\hline Black & -0.81 & -1.15 to 0.46 \\
\hline \multicolumn{3}{|l|}{ Path A } \\
\hline Poor & 1.14 & 0.71 to 1.57 \\
\hline College & -1.64 & -2.15 to -1.14 \\
\hline Married & -1.52 & -1.94 to -1.10 \\
\hline \multicolumn{3}{|l|}{ Path B and Path $\mathrm{C}^{\prime}$} \\
\hline Poor & -0.44 & -0.71 to -0.17 \\
\hline College & 1.64 & 1.00 to 2.28 \\
\hline Married & 0.99 & 0.56 to 1.41 \\
\hline Black & 0.26 & -0.17 to 0.69 \\
\hline \multicolumn{3}{|c|}{ Breastfeeding postnatal intent } \\
\hline \multicolumn{3}{|l|}{ Path C } \\
\hline Black & -1.02 & -1.35 to -0.68 \\
\hline \multicolumn{3}{|l|}{ Path A } \\
\hline Poor & 1.14 & 0.71 to 1.57 \\
\hline College & -1.64 & -2.15 to -1.14 \\
\hline Married & -1.52 & -1.94 to -1.10 \\
\hline \multicolumn{3}{|l|}{ Path B and Path $C^{\prime}$} \\
\hline Poor & -0.56 & -0.83 to -0.29 \\
\hline College & 1.73 & 1.09 to 2.37 \\
\hline Married & 1.02 & 0.61 to 1.44 \\
\hline Black & 0.13 & -0.29 to 0.55 \\
\hline \multicolumn{3}{|l|}{ Breastfeeding duration } \\
\hline \multicolumn{3}{|l|}{ Path C } \\
\hline Black & -10.31 & -12.04 to -8.58 \\
\hline \multicolumn{3}{|l|}{ Path A } \\
\hline College & -0.29 & -0.35 to -0.23 \\
\hline Married & -0.24 & -0.30 to -0.19 \\
\hline Hospital formula & -0.08 & -0.03 to -0.12 \\
\hline \multicolumn{3}{|l|}{ Path B and Path $\mathrm{C}^{\prime}$} \\
\hline College & 6.54 & 4.26 to 8.81 \\
\hline Married & 4.34 & 2.52 to 6.17 \\
\hline Hospital formula & -9.79 & -11.43 to -8.16 \\
\hline Black & -1.51 & -3.36 to 0.34 \\
\hline
\end{tabular}

In these models, white mothers were coded as 0 , and black mothers were coded as 1 .

TABLE 4 Mediation of Differences in Breastfeeding Initiation, Postnatal Intent, and Duration Between White and Spanish-speaking Hispanic Mothers

\begin{tabular}{|c|c|c|}
\hline Variable & $\beta$ & 95\% Confidence Interval \\
\hline \multicolumn{3}{|l|}{ Breastfeeding initiation } \\
\hline \multicolumn{3}{|l|}{ Path C } \\
\hline Hispanic, Spanish-speaking & 0.84 & 0.23 to 1.44 \\
\hline \multicolumn{3}{|l|}{ Path A } \\
\hline Maternal grandmother breastfed & 1.66 & 1.04 to 2.27 \\
\hline \multicolumn{3}{|l|}{ Path $B$ and Path $C^{\prime}$} \\
\hline Maternal grandmother breastfed & 0.75 & 0.09 to 1.42 \\
\hline Hispanic, Spanish-speaking & 0.55 & -0.09 to 1.19 \\
\hline \multicolumn{3}{|l|}{ Breastfeeding postnatal intent } \\
\hline \multicolumn{3}{|l|}{ Path Ca } \\
\hline Hispanic, Spanish-speaking & 0.94 & 0.33 to 1.52 \\
\hline \multicolumn{3}{|l|}{ Breastfeeding duration } \\
\hline \multicolumn{3}{|l|}{ Path $\mathrm{C}^{\mathrm{a}}$} \\
\hline Hispanic, Spanish-speaking & -2.08 & -4.91 to 0.75 \\
\hline
\end{tabular}

In these models, white mothers were coded as 0 , and Spanish-speaking Hispanic mothers were coded as 1.

a Denotes contrasts in which no mediators were identified. 
mother who breastfed also partially mediated the difference in postnatal intent (Table 6, Path $\mathrm{C}^{\prime}$ ).

\section{Duration}

Black mothers nursed an estimated 10.3 weeks less than did Spanishspeaking Hispanic mothers (Table 6, Path C). Again, black mothers were less likely to have a family history of breastfeeding but were also less likely to live with the infant's father (Table 6, Path A). Together, these 2 variables partially explained the large gap in duration (Table 6, Path $\mathrm{C}^{\prime}$ ).

\section{Disparities Between Black and English-speaking Hispanic Motherse}

\section{Initiation}

English-speaking Hispanic mothers initiated breastfeeding more often than did black mothers (Table 7, Path C). Mothers whose own mothers had breastfed were more prevalent among English-speakers than black mothers (Table 7, Path A), which partially mediated the initiation gap (Table 7, Path C').

\section{Postnatal Intent}

English-speaking Hispanic mothers were more likely to intend to breastfeed than were black mothers (Table 7, Path C). English-speaking Hispanic mothers were also more likely to have maternal and paternal mothers who had breastfed (Table 7, Path A). In this model, both family history variables predicted unique variations in postnatal intent and partially mediated the racial/ethnic gap in intent (Table 7 , Paths $\mathrm{B}$ and $\mathrm{C}^{\prime}$ ).

\section{Duration:}

Black women weaned their infants $\sim 3.0$ weeks earlier than Englishspeaking Hispanic women (Table 7, Path C). Black mothers were less likely to be married or have a maternal history of breastfeeding than English-speaking Hispanic

TABLE 5 Mediation of Differences in Breastfeeding Initiation, Postnatal Intent, and Duration Between White and English-speaking Hispanic Mothers

\begin{tabular}{|c|c|c|}
\hline Variable & $\beta$ & 95\% Confidence Interval \\
\hline \multicolumn{3}{|l|}{ Breastfeeding initiation } \\
\hline \multicolumn{3}{|l|}{ Path C } \\
\hline Hispanic, English-speaking & 0.77 & 0.11 to 1.42 \\
\hline \multicolumn{3}{|l|}{ Path A } \\
\hline Maternal grandmother breastfed & 0.60 & 0.02 to 0.06 \\
\hline \multicolumn{3}{|l|}{ Path B and Path $C^{\prime}$} \\
\hline Maternal grandmother breastfed & 0.71 & 0.02 to 1.41 \\
\hline Hispanic, English-speaking & 0.66 & -0.01 to 1.32 \\
\hline \multicolumn{3}{|l|}{ Breastfeeding postnatal intent } \\
\hline \multicolumn{3}{|l|}{ Path Ca } \\
\hline Hispanic, English-speaking & 0.66 & 0.04 to 1.27 \\
\hline \multicolumn{3}{|l|}{ Breastfeeding duration } \\
\hline \multicolumn{3}{|l|}{ Path C } \\
\hline Hispanic, English-speaking & -6.89 & -9.99 to -3.79 \\
\hline \multicolumn{3}{|l|}{ Path A } \\
\hline College & -0.28 & -0.41 to -0.16 \\
\hline Age & -0.02 & -0.03 to -0.01 \\
\hline \multicolumn{3}{|l|}{ Path B and Path $\mathrm{C}^{\prime}$} \\
\hline College & 5.57 & 1.61 to 9.53 \\
\hline Age & 0.84 & 0.53 to 1.14 \\
\hline Hispanic, English-speaking & -0.03 & -3.36 to 3.29 \\
\hline
\end{tabular}

In these models, white mothers were coded as 0 , and English-speaking Hispanic mothers were coded as 1.

a Denotes contrasts in which no mediators were identified.

TABLE 6 Mediation of Differences in Breastfeeding Initiation, Postnatal Intent, and Duration Between Black and Spanish-speaking Hispanic Mothers

\begin{tabular}{|c|c|c|}
\hline Variable & $\beta$ & 95\% Confidence Interval \\
\hline \multicolumn{3}{|l|}{ Breastfeeding initiation } \\
\hline \multicolumn{3}{|l|}{ Path C } \\
\hline Black & -1.57 & -2.04 to -1.10 \\
\hline \multicolumn{3}{|l|}{ Path A } \\
\hline Maternal grandmother breastfed & -2.84 & -3.56 to -2.11 \\
\hline \multicolumn{3}{|l|}{ Path B and Path $C^{\prime}$} \\
\hline Maternal grandmother breastfed & 0.90 & 0.37 to 1.43 \\
\hline Black & -1.12 & -1.66 to -0.57 \\
\hline \multicolumn{3}{|l|}{ Breastfeeding postnatal intent } \\
\hline \multicolumn{3}{|l|}{ Path C } \\
\hline Black & -1.64 & -2.11 to -1.16 \\
\hline \multicolumn{3}{|l|}{ Path A } \\
\hline Maternal grandmother breastfed & -2.84 & -3.56 to -2.11 \\
\hline \multicolumn{3}{|l|}{ Path B and Path $\mathrm{C}^{\prime}$} \\
\hline Maternal grandmother breastfed & 1.21 & 0.60 to 1.82 \\
\hline Black & -1.04 & -1.60 to -0.48 \\
\hline \multicolumn{3}{|l|}{ Breastfeeding duration } \\
\hline \multicolumn{3}{|l|}{ Path C } \\
\hline Black & -10.25 & -12.30 to -8.21 \\
\hline \multicolumn{3}{|l|}{ Path A } \\
\hline Coresident father & -0.27 & -0.33 to -0.21 \\
\hline Maternal grandmother breastfed & -0.36 & -0.43 to -0.29 \\
\hline \multicolumn{3}{|l|}{ Path B and Path $C^{\prime}$} \\
\hline Coresident father & 4.07 & 2.09 to 6.04 \\
\hline Maternal grandmother breastfed & 4.68 & 2.55 to 6.81 \\
\hline Black & -6.07 & -8.49 to -3.65 \\
\hline
\end{tabular}

In these models, black mothers were coded as 0 , and Spanish-speaking Hispanic mothers were coded as 1 .

mothers (Table 7, Path A). Both variables fully mediated the disparity in duration (Table 7 , Path $\mathrm{C}^{\prime}$ ).

\section{DISCUSSION}

In line with previous reports, ${ }^{2,5}$

black mothers in the current sample 
TABLE 7 Mediation of Differences in Breastfeeding Initiation, Postnatal Intent, and Duration Between Black and English-speaking Hispanic Mothers

\begin{tabular}{|c|c|c|}
\hline Variable & $\beta$ & 95\% Confidence Interval \\
\hline \multicolumn{3}{|l|}{ Breastfeeding initiation } \\
\hline \multicolumn{3}{|l|}{ Path C } \\
\hline Black & -1.45 & -2.04 to -0.87 \\
\hline \multicolumn{3}{|l|}{ Path A } \\
\hline Maternal grandmother breastfed & -1.66 & -2.36 to -0.96 \\
\hline \multicolumn{3}{|l|}{ Path B and Path $C^{\prime}$} \\
\hline Maternal grandmother breastfed & 0.88 & 0.36 to 1.39 \\
\hline Black & -1.19 & -1.80 to -0.58 \\
\hline \multicolumn{3}{|l|}{ Breastfeeding postnatal intent } \\
\hline \multicolumn{3}{|l|}{ Path C } \\
\hline Black & -1.26 & -1.80 to -0.71 \\
\hline \multicolumn{3}{|l|}{ Path A } \\
\hline Maternal grandmother breastfed & -1.32 & -2.04 to -0.59 \\
\hline Paternal grandmother breastfed & -1.14 & -1.81 to -0.47 \\
\hline \multicolumn{3}{|l|}{ Path B and Path C' } \\
\hline Maternal grandmother breastfed & 1.06 & 0.43 to 1.69 \\
\hline Paternal grandmother breastfed & 0.72 & 0.19 to 1.24 \\
\hline Black & -0.78 & -1.37 to -0.19 \\
\hline \multicolumn{3}{|l|}{ Breastfeeding duration } \\
\hline \multicolumn{3}{|l|}{ Path C } \\
\hline Black & -3.03 & -5.16 to -0.90 \\
\hline \multicolumn{3}{|l|}{ Path A } \\
\hline Married & -0.08 & -0.15 to -0.02 \\
\hline Maternal grandmother breastfed & -0.17 & -0.24 to -0.11 \\
\hline \multicolumn{3}{|l|}{ Path B and Path $C^{\prime}$} \\
\hline Married & 7.25 & 4.92 to 9.58 \\
\hline Maternal grandmother breastfed & 4.47 & 2.50 to 6.43 \\
\hline Black & 0.11 & -2.02 to 2.25 \\
\hline
\end{tabular}

In these models, black mothers were coded as 0, and English-speaking Hispanic mothers were coded as 1.

intended, initiated, and maintained breastfeeding to a lesser degree than white mothers. Lower levels of breastfeeding initiation and postnatal intent among black mothers compared with white mothers were fully mediated by demographic factors. This finding is not surprising given that black women had higher rates of poverty and lower levels of education and marriage, variables that predicted lower rates of breastfeeding initiation and postnatal intent in the overall sample. Breastfeeding duration disparities between black and white women, however, were not fully explained by using demographic factors.

Poverty did not significantly mediate differences in duration between black and white mothers as it did for initiation and postnatal intent. Poverty may act as a proxy for in-hospital formula introduction, which more often occurs in predominately black communities that may also be low-income. ${ }^{27}$ In fact, the use of in-hospital formula feeding played the most important role for duration. Black mothers' newborns were much more likely to be fed formula in the hospital than newborns of white mothers. This difference was not explained by higher rates of breastfeeding intent and initiation in white mothers. Our finding echoes reports from the Centers for Disease Control and Prevention that documented higher rates of supplemental feeding in hospitals serving black communities. In-hospital supplementation of formula prohibits establishing a pattern of exclusive breastfeeding early on, which has been shown to hinder breastfeeding outcomes postdischarge. ${ }^{28}$ Our study suggests that if only hospital formula introduction were eliminated, the black/white gap in breastfeeding duration could be reduced by $\sim 1.8$ weeks or $20 \%$ of the overall difference.

Consistent with notions that cultural norms regarding breastfeeding practices drive the effect of acculturation/immigrant status on breastfeeding outcomes, Spanishspeaking Hispanic women were more likely to have a family history of breastfeeding compared with white and English-speaking Hispanic women. Maternal family history of breastfeeding fully mediated the initiation disparity between white and both Spanish-and Englishspeaking Hispanic mothers. Racial/ ethnic differences in maternal age and education fully explained disparities in duration between white and English-speaking Hispanic mothers. No mediators were found for postnatal intent or duration among Spanish-speaking Hispanic and white mothers, which speaks to previous evidence of the Hispanic paradox in US breastfeeding rates. ${ }^{29}$ This paradox is a phenomenon in which Hispanic people in the United States experience good health outcomes despite low SES and common risk factors, particularly among recent immigrants. ${ }^{30}$ Comparable duration of breastsfeeding between white and Spanish-speaking Hispanic women in our sample suggests that breastfeeding norms of Spanish speakers' native countries ${ }^{31}$ may overcome adverse effects of low SES that characterizes this less acculturated group in the United States. It is also notable that no significant racial/ethnic differences were found in the belief that "breast is best" or maternal employment at 1 month postpartum, because both factors have been hypothesized to mediate racial/ethnic breastfeeding. ${ }^{32}$ It is possible, however, that the oversampling of low SES participants of all racial/ethnic groups in this study restricted variability on these factors, leading to null results.

Family history of breastfeeding, especially from the mother's side, 
bolsters breastfeeding outcomes, and this intergenerational factor mediates racial/ethnic breastfeeding disparities. This finding complements previous research which found that markers of acculturation, such as language spoken at home, ${ }^{8}$ predict substantial differences in breastfeeding behavior. ${ }^{9,33}$ In addition to family history of breastfeeding, higher rates of coresident fathers and marriage among Hispanic women accounted for some of the breastfeeding disparities between black and both English- and Spanish-speaking Hispanic women. This finding supports previous research showing the important role that the infant's father can play in fostering positive breastfeeding outcomes. ${ }^{34}$

The current study had several limitations. We cannot establish causality; interventions are needed to test whether decreasing the introduction of formula in hospitals serving black communities, for example, would reduce disparities between black and white women in breastfeeding duration. Second, this study included an overrepresentation of mothers of low SES, and the results may not be generalizable to understanding racial/ethnic disparities in breastfeeding rates between white, black, and Hispanic mothers among the middle- or upper-class. Finally, future research is needed to explore additional potential mediators because many racial/ ethnic disparities in breastfeeding were not fully explained by our analyses.

\section{CONCLUSIONS}

Large ethnic/racial gaps in breastfeeding rates exist in the United States among black, white, and Hispanic infants and their mothers. In line with previous speculations, intergenerational experience with breastfeeding seems to be an important predictor of infant feeding behaviors and helps explain why Hispanic women have better breastfeeding outcomes. Just as importantly, the negative impact of hospital infant formula feeding practices on black women warrants strong consideration. ${ }^{35}$ Changing hospital relationships with formula companies that relinquish fiscal dependency on free formula is a notorious challenge for many hospitals that strive to improve breastfeeding outcomes. ${ }^{36}$ Change is possible, however, as evidenced by the emergence of "baby-friendly hospitals," some of which serve areas with largely low-income and minority patient populations. ${ }^{37}$ This active inquiry into functional variables that can yield healthier outcomes for infants and mothers has produced new findings and may support planned interventions at the levels of individual families and health care providers.

\section{ABBREVIATION}

SES: socioeconomic status

and critically reviewed the initial manuscript; Dr Raju provided Eunice Kennedy Shriver National Institute of Child Health and Human Development leadership for the Community and Child Health Network and critically reviewed the initial manuscript; Dr Shalowitz helped conceptualize the study, helped design data collection instruments, coordinated and supervised data collection, and critically reviewed and gave feedback on the initial and revised manuscripts; and all authors approved the final manuscript as submitted.

DOI: $10.1542 /$ peds.2015-2388

Accepted for publication May 11, 2016

Address correspondence to Chelsea 0. McKinney, PhD, MPH, NorthShore University HealthSystem Department of Pediatrics and Research Institute, 1001 University Place, Suite 348, Evanston, IL 60201. E-mail: chelseaomckinney@gmail.com

PEDIATRICS (ISSN Numbers: Print, 0031-4005; Online, 1098-4275).

Copyright $(2016$ by the American Academy of Pediatrics

FINANCIAL DISCLOSURE: The authors have indicated they have no financial relationships relevant to this article to disclose.

FUNDING: All phases of this study were supported by grants to the Community and Child Health Network through cooperative agreements with the Eunice Kennedy Shriver National Institute of Child Health and Human Development (UHD44207, U HD44219, UHD44226, U HD44245, U HD44253, U HD54791, U HD54019, UHD44226-05S1, U HD44245-06S1, and R03 HD59584) and the National Institute for Nursing Research (U NR008929). Funded by the National Institutes of Health (NIH).

POTENTIAL CONFLICT OF INTEREST: The authors have indicated they have no potential conflicts of interest to disclose.

\section{REFERENCES}

1. American Academy of Pediatrics Section on Breastfeeding. Policy statement: breastfeeding and the use of human milk. Pediatrics. 2012;129(3). Available at: www.pediatrics.org/cgi/ content/full/129/3/e827
2. Centers for Disease Control and Prevention. Breastfeeding among US children born 2002-2012, national immunization surveys. Available at: www.cdc.gov/ breastfeeding/data/nis_data/ rates-any-exclusive-bf-socio-dem-2012. htm

3. Bartick M, Reinhold A. The burden of suboptimal breastfeeding in the United States: a pediatric cost analysis. 
Pediatrics. 2010;125(5). Available at: www.pediatrics.org/cgi/content/full/ 125/5/e1048

4. Bartick MC, Stuebe AM, Schwarz EB, Luongo C, Reinhold AG, Foster EM. Cost analysis of maternal disease associated with suboptimal breastfeeding. Obstet Gynecol. 2013;122(1):111-119

5. Grummer-Strawn LM, Shealy KR. Progress in protecting, promoting, and supporting breastfeeding: 1984-2009. Breastfeed Med. 2009;4 (suppl 1):S31-S39

6. Centers for Disease Control and Prevention (CDC). Racial and socioeconomic disparities in breastfeeding - United States, 2004. MMWR Morb Mortal Wkly Rep. 2006;55(12):335-339

7. Li R, Grummer-Strawn L. Racial and ethnic disparities in breastfeeding among United States infants: Third National Health and Nutrition Examination Survey, 1988-1994. Birth 2002;29(4):251-257

8. Berry JW. Immigration, acculturation, and adaptation. Appl Psychol. 1997:46(1):5-34

9. Singh GK, Kogan MD, Dee DL. Nativity/immigrant status, race/ ethnicity, and socioeconomic determinants of breastfeeding initiation and duration in the United States, 2003. Pediatrics. 2007;119(suppl 1):S38-S46

10. US Department of Health and Human Services, Health Resources and Services Administration. Women's Health USA 2011. Rockville, MD: US Department of Health and Human Services; 2011

11. Ryan AS, Zhou W, Arensberg MB. The effect of employment status on breastfeeding in the United States. Womens Health Issues. 2006;16(5):243-251

12. Sebelius K. Annual Update of the HHS Poverty Guidelines. Washington, DC: US Department of Health and Human Services; 2011

13. Kiernan K, Pickett KE. Marital status disparities in maternal smoking during pregnancy, breastfeeding and maternal depression. Soc Sci Med. 2006;63(2):335-346

14. Jones JR, Kogan MD, Singh GK, Dee DL, Grummer-Strawn LM. Factors associated with exclusive breastfeeding in the United States. Pediatrics. 2011;128(6):1117-1125

15. Pilkauskas NV. Breastfeeding initiation and duration in coresident grandparent, mother and infant households. Matern Child Health J. 2014;18(8):1955-1963

16. Dennis CL, McQueen K. The relationship between infant-feeding outcomes and postpartum depression: a qualitative systematic review. Pediatrics. 2009;123(4). Available at: www. pediatrics.org/cgi/content/full/123/4/ e736

17. Cox JL, Holden JM, Sagovsky R. Detection of postnatal depression. Development of the 10-item Edinburgh Postnatal Depression Scale. Br J Psychiatry. 1987;150:782-786

18. Liu J, Rosenberg KD, Sandoval AP. Breastfeeding duration and perinatal cigarette smoking in a populationbased cohort. Am J Public Health. 2006;96(2):309-314

19. Callen J, Pinelli J. A review of the literature examining the benefits and challenges, incidence and duration, and barriers to breastfeeding in preterm infants. Adv Neonatal Care. 2005;5(2):72-88, quiz 89-92

20. Bentley ME, Dee DL, Jensen JL. Breastfeeding among low income, African-American women: power, beliefs and decision making. J Nutr. 2003;133(1):305S-309S

21. Cox KN, Giglia RC, Binns CW. The influence of infant feeding attitudes on breastfeeding duration: evidence from a cohort study in rural Western Australia. Int Breastfeed J. 2015;10(25):25

22. Ryan AS, Zhou W. Lower breastfeeding rates persist among the Special Supplemental Nutrition Program for Women, Infants, and Children participants, 1978-2003. Pediatrics. 2006;117(4):1136-1146

23. Centers for Disease Control and Prevention (CDC). Breastfeedingrelated maternity practices at hospitals and birth centers-United
States, 2007. MMWR Morb Mortal Wkly Rep. 2008;57(23):621-625

24. Raudenbush SW, Bryk AS. Hierarchical Linear Models: Applications and Data Analysis Methods. Thousand Oaks, CA: Sage Publications; 2002

25. Baron RM, Kenny DA. The moderatormediator variable distinction in social psychological research: conceptual, strategic, and statistical considerations. J Pers Soc Psychol. 1986;51(6):1173-1182

26. Preacher KJ, Hayes AF. Asymptotic and resampling strategies for assessing and comparing indirect effects in multiple mediator models. Behav Res Methods 2008;40(3):879-891

27. Lind JN, Perrine CG, Li R, Scanlon KS, Grummer-Strawn LM; Centers for Disease Control and Prevention (CDC). Racial disparities in access to maternity care practices that support breastfeeding-United States, 2011. MMWR Morb Mortal Wkly Rep. 2014;63(33):725-728

28. UNICEF/WHO. Baby-friendly hospital initiative: revised, updated and expanded for integrated care, section 1, background and implementation, preliminary version. Available at: www.who.int/nutrition/topics/BFH_ Revised_Section1.pdf. Accessed May 5, 2008

29. Kimbro RT, Lynch SM, McLanahan S. The influence of acculturation on breastfeeding initiation and duration for Mexican-Americans. Popul Res Policy Rev. 2008;27 (2): 183-199

30. Franzini L, Ribble JC, Keddie AM. Understanding the Hispanic paradox. Ethn Dis. 2001;11(3):496-518

31. Lauer JA, Betrán AP, Victora CG, de Onís M, Barros AJ. Breastfeeding patterns and exposure to suboptimal breastfeeding among children in developing countries: review and analysis of nationally representative surveys. BMC Med. 2004;2 (26):26

32. Centers for Disease Control and Prevention (CDC). Progress in increasing breastfeeding and reducing racial/ethnic differences-United States, 2000-2008 births. MMWR Morb Mortal Wkly Rep. 2013;62(5):77-80 
33. Topolyan I, Wang Q, Xu X. Peer effects in breastfeeding: evidence from the IFPS II Study. Review of Economics and Finance. 2015;5(3):33-44

34. Pisacane A, Continisio Gl, Aldinucci M, D’Amora S, Continisio P. A controlled trial of the father's role in breastfeeding promotion. Pediatrics. 2005;116(4). Available at: www. pediatrics.org/cgi/content/full/116/4/ e494

35. Radford A, Southall DP. Successful application of the baby-friendly hospital initiative contains lessons that must be applied to the control of formula feeding in hospitals in industrialized countries. Pediatrics. 2001;108(3):766-768
36. Merewood A, Philipp BL. Becoming baby-friendly: overcoming the issue of accepting free formula. $J$ Hum Lact. 2000;16(4): 279-282

37. Merewood A, Philipp BL. Implementing change: becoming baby-friendly in an inner city hospital. Birth. 2001;28(1):36-40 